\title{
Promoting adaptive flood risk management: the role and potential of flood recovery mechanisms
}

\author{
Sally J Priest ${ }^{1, a}$, Edmund C. Penning-Rowsell ${ }^{1}$ and Cathy Suykens ${ }^{2}$ \\ ${ }^{1}$ Flood Hazard Research Centre, Middlesex University, London, NW4 4BT, United Kingdom \\ ${ }^{2}$ Institute for Environmental and Energy Law, KU Leuven, Leuven, Belgium
}

\begin{abstract}
There is a high potential for recovery mechanisms to be used to incentivise the uptake of flood mitigation and loss reduction measures, undertake adaptation and promote community resilience. Indeed, creating a resilient response to flooding requires flood risk management approaches to be aligned and it needs to be ensured that recovery mechanisms to not provide disincentives for individuals and business to take proactive action to reduce risk. However, the degree to which it is desirable and effective for insurers and governments providing compensation to promote resilience and risk reduction depends upon how the cover or compensation is organised and the premiums which are charged. A review of international flood recovery mechanisms has been undertaken to identify firstly the types of schemes that exist and their characteristics. Analysis of existing instruments highlights that there are various potential approaches to encourage or require the uptake of flood mitigation and also discourage the construction of new development in high flood risk. However despite the presence of these instruments, those organising recovery mechanisms could be doing much more to incentivise increased resilience.
\end{abstract}

\section{Introduction}

There are many ways in which those who suffer the impacts of flooding can financially recover from losses. These mechanisms can be broadly characterised by the level to which those who receive financial assistance, directly pay for the recovery mechanism and the formality and rigidity of the device. Widely available flood insurance within a well-functioning and solvent market has the potential to not only assist the recovery from hazard events; but also positively influence mitigation behaviour. However, the characteristics of current flood insurance models and their effectiveness vary considerably between countries. How flood insurance provision is structured, what losses are covered and excluded and how it is purchased all impact upon the effectiveness of the scheme for recovering from flood losses and ultimately how burden sharing is split between the at-risk individual and society.

\section{The varying roles of insurance and recovery}

The primary function of flood recovery mechanisms is to allow individuals and business to recover financially from the damages and losses sustained during flooding. However, certain types of recovery can provide other positive functions. For instance, Sayers et al. [1; p187] identify four main roles of flood insurance:

\footnotetext{
a Corresponding author: $\underline{\text { S.Priest@mdx.ac.uk }}$
}

1. Reimbursing those who suffer damage, and thereby restoring them to their pre-flood financial situation.

2. Spreading the costs of flooding across communities (and clients), given that floods may affect only some communities at a time; and for individuals through time by spreading the potential costs of flood damage over many years in relatively small payments rather than having a single large cost if, and when, a flood actually occurs.

3. Reducing the costs to the government of post-event recovery since the insured will receive insurance funds (note: where a private insurance sector exists only)

4. Promoting a change of behaviour with regard to exposure to flood risk, by giving a signal of the hazard that people face and providing incentives for "good behaviour."

Although a recovery mechanism can provide financial recompense following flooding, it is important that it does not act in a way which encourages an increase in risk and/or behaviour leads to increased damages. This paper therefore considers the fourth of the roles presented above and examines how, and the extent to which, different types of recovery measures can promote risk reduction action by individual householders, business owners or governments. 


\section{Methods}

Over thirty international recovery mechanisms have been reviewed as part of a desk-based analysis supplemented by qualitative interviews - to identify the potential and barriers of different types of approaches. Analysis has focussed on not only the potential for the promotion of adaptation to flood risk, but also on the effectiveness of current approaches in delivering risk reduction. Before discussing potential risk reduction instruments it is important to briefly introduce different types of recovery mechanisms.

\section{Types of flood recovery mechanisms}

Priest [2] provides a straightforward typology highlighting four types of flood-recovery options. This categorisation varies by the directness of financial input by the individual:

- Loss bearing - The victim carries all of the losses.

- Loss sharing - This involves spreading the losses more widely. One type of formalised mechanism is flood insurance. The victim contributes through premium payments, but does not bear the total loss.

- Compensation - A more social device. National, regional or local governments provide financial assistance to those affected by flooding. The victim generally contributes through taxation, but does not bear the total loss.

- Charitable/ International aid - Financial assistance provided through donations which may be from inside or outside of the area affected. The victim does not contribute directly to the losses.

A number of studies have aimed to model and categorise flood recovery, insurance and compensation mechanisms (notably [3, 4, 5 and 6]). The research presented here builds on this work, but broadens the discussion to encompass all types of flood recovery mechanisms. Figure 1 presents a categorisation of international recovery types. These have been divided according to the following criteria; whether flooding is a bundled risk or offered as a single peril, if insurance is provided or backed by the government and whether if it is compulsory (those in italics). Figure 2 presents compensation approaches divided according to: whether a scheme and the relevant rules are established prior to an event occurring or are established on an ad hoc basis and whether the financing of the schemes are established in systematic way prior to the event occurring (ex ante) or if funding has to be found after the event (ex post). Where a country has more than one type of recovery system available they will appear more than once in the figures. The figures are drawn after Table 6.5 in [7] and based on information in [5, 8-12].

\section{Private market (operates on an individual market basis)}

Australia, Denmark (non-sea flooding, Germany, Indonesia, Italy, Poland, Taiwan,
Argentina, Australia, Austria, Brazil, China Ecuador, Germany, Israel, Japan, Mexico, the Netherlands (rainfall and SWF), New Zealand, Philippines, Portugal, Sweden
Individual peril

Pooled system (private insurance market led-different pools e.g. single/bundled perils)

$$
\left\{\begin{array}{c}
\text { Norway, Romania, } \\
\text { Switzerland (GUSTAVO), } \\
\text { UK (post-2016) }
\end{array}\right.
$$

Bundled with other perils

Pooled system (high degree of state involvement/ backing)

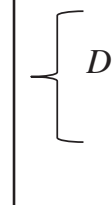

Denmark (sea flooding), France, Iceland

Spain, Switzerland,

(Cantonal) United States

State run (and subsidised)

Figure 1. International examples of insurance cover. 


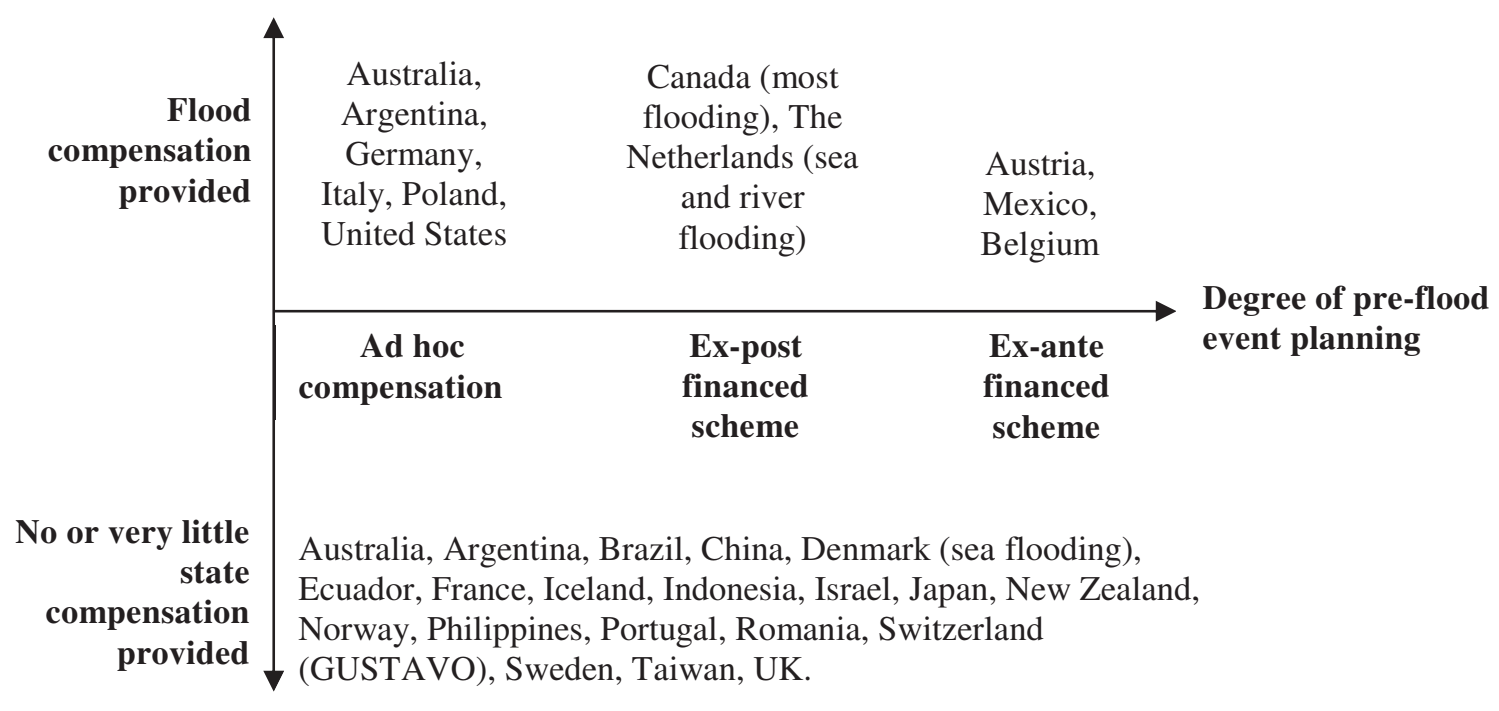

Figure 2. International examples of compensation schemes

\section{The role of recovery mechanisms in encouraging risk reduction action}

There is a high potential for insurance cover to be used to incentivise the uptake of flood mitigation and loss reduction measures, undertake adaptation and promote community resilience. As Kunreuther [13; p180] argues that "In theory, insurance is one of the most effective policy tools for achieving both objectives, because it rewards investments in cost-effective mitigation with lower premiums and provides indemnification should a disaster occur". He goes on to state that insurance is a "potentially valuable tool for encouraging loss reduction measures against natural hazards and for providing recovery funds to disaster victims" [13]. However, the degree to which it is desirable for insurers to promote resilience and risk reduction depends upon how the cover is organised and the premiums which are charged. Theoretically, if individual insurers have a good understanding of flood risk, are able to assess the risk well enough to effectively price that risk and achieve actuarially-price premiums from customers there insurers would have little interest or need to be concerned about the degree of risk nor the need to incentivise resilience behaviour. However, from the international examples, insurance systems which satisfy these conditions remain limited.

The types of exposure being covered and the nature of adverse natural events means that private insurers are not able to take on these risks alone, they are also reliant on other mechanisms to assist in risk management. Consequently, there is often the need to require the active involvement and agreement of other parties such as government agencies, building contractors and financial institutions to ensure that other policy tools (e.g. construction codes, risk reduction measures) are implemented [13]. Additionally, it is not only insurance that can contribute to risk reduction; placing requirements on victims receiving compensation can also be effective in incentivising risk reduction measures.

There is a wide variety of ways in which flood mitigation and risk reduction activities may be introduced and at a variety of scales; from individual household level measures, to community resilience schemes, up to regional or national strategies. Insurers and insurance schemes may impact upon all of these levels although the instrument that they achieve this (e.g. lobbying government, placing restrictions on coverage, offering a reduction in premium) to incentivise mitigation can vary considerably. Importantly, many of the insurance or compensation schemes reviewed appeared to have no or very few measures to encourage risk reduction action. Of those that do, the overall uptake (penetration) of the approach is important as if few people have insurance or will receive compensation then the impact that any incentivising actions have will be reduced.

Similarly, the availability of multiple flood recovery mechanisms in one location is important to consider in the context of risk reduction. There is some evidence to suggest that the presence of government compensation provides a disincentive for individuals to purchase their own insurance and consequently in these situations (such as Austria or Italy) insurance penetration is low. This will of course reduce the influence and effectiveness of any requirements that insurers might make or any incentives that they introduce.

The following sections describe some of the key ways in recovery mechanisms incentivise risk reduction action. These have been identified from the review of international flood recovery measures and include a mix of measures which either incentivise or require risk reduction action and those that dis-incentivise living in flood risk areas. Importantly, the categories are not necessarily mutually exclusive and any one recovery system may have more than one of these measures to try to incentivise risk reduction. Table 1 provides a summary of the possible instruments used to promote risk reduction and examples of where it has been implemented. 


\subsection{Excluding properties from cover}

Excluding properties from cover is a relatively common mechanism which is used to try to reduce both the exposure of insurance companies or compensation funds. A range of different types of properties were observed to be excluded for different reasons. The first category is those properties most at risk from flooding and for which insurers consider too risky to cover. These might be excluded directly with an insurer refusing to offer any kind of cover. Secondly, an insurer may increase a premium to such a high price that it becomes unaffordable and, as such, is indirectly excluding that property from coverage. This situation was observed in Germany where areas have been categorised by flood risk (ZÜRS) of which the highest (probability of flooding is greater than 1 in 10 years) is considered to be uninsurable $[12,14]$. However, the non-compulsory nature of flood insurance in Germany means that the impact of these actions will be limited. Despite this, the uncertainty surrounding the amount of compensation that might be received (in Germany the approach to compensation is ad hoc) may be enough to incentivise those at high risk of flooding to take some action.

A second category of exclusion relates to whether some categories of the property or contents are excluded. For instance, in Italy as well as some entire properties being excluded, there was also evidence that there are exclusions placed upon contents located on the ground floor up to a certain height (e.g. 20 or $30 \mathrm{~cm}$ ) [10]. This may have the impact of incentivising the uptake of individual property resilience or resistance measures and in particular for people to take action to save contents (e.g. by moving it upstairs) prior to, or during, a flood event.

One of the most common property types excluded from flood coverage is newly built homes. Linking closely with spatial planning, insurers and governments want to avoid increasing the numbers of properties at risk of flooding. The refusal of insurance, or not being entitled to premium reductions, may have the power to motivate some people to reduce their flood risk in order to try to obtain insurance. However, the degree to which an exclusion of insurance coverage acts as a deterrent for development in areas of flood risk is debatable This is likely to be most powerful where there is some compulsion to purchase insurance, including situations where there is the need to have insurance to secure a mortgage, however in other situations whereby insurance is optional it may have little effect. Not being able to secure insurance on a house may have severe implications including defaulting on the terms and conditions on an existing home loan. It may also limit the potential opportunities for selling the property and affect its resale value if potential buyers are unable to secure a mortgage. This condition was found in a number of international examples reviewed in this study; e.g. Belgium, Norway, Denmark, United Kingdom and France. In order to be most effective insurance coverage needs to be widespread for a significant impact. There is little direct and demonstrable evidence that restrictions of insurance cover have had a verifiable impact on the reduction of development in the floodplain [15].

\subsection{Minimum standards or special conditions imposed on properties}

A further incentive for risk reduction is through the placement of special conditions on policyholders if they wish to purchase insurance or receive compensation following an event. One such special condition might be that a householder has adopted property level resilience or resistance measures to reduce the susceptibility of the property to loss. Both Denmark and Iceland have inclusions within policies that if properties have been flooded in the past then there is the need to adopt preventative measures and that insurance can be reduced or refused if this is not undertaken [12]. However, similar to the Belgian situation, it is unclear how often these clauses are invoked and cover is actually refused.

The most comprehensive approach which is trying to encourage mitigation, often through the raising of properties, is the National Flood Insurance Programme in the United States [16]. This insurance scheme has many conditions relating to risk reduction and communities are only permitted to enter the insurance scheme if they participate fully in complying with the requirement to undertake risk assessment and then further mitigation activities. Despite the good intentions however, due to a lack of enforcement and the often disputed risk assessment process, it is unclear the extent to which the NFIP has impacted positively on risk reduction [17]. This is one of the aspects that is hoped will be improved upon under the new reformed program [18].

Building codes and special building regulations have often been considered to be fundamental to insurers reducing their risk from future losses [13, 19]. Unsurprisingly, insurers seemed to be most interested in the structural integrity of dwellings, but perhaps less interested in other aspects of resilient design that may reduce losses. There were many instances within the international review that made the adherence to building codes or construction standards a requirement for the availability of insurance or the receipt of financial recovery if flooded. It was also possible for insurance to be removed or refused for properties that were considered to be poorly constructed or poorly maintained. International examples which mentioned building regulations of this nature include Spain, Turkey, Iceland, Norway and Romania. However, many of these named schemes are for multiple hazards and the construction standards often were mainly concerned with the structural integrity to earthquakes. It was not clear if there were additional requirements for flood or how earthquake resilient properties might fair during flood events. Despite this ambiguity there is no reason why requiring certain building standards or the retrofitting of resilience or resistance measures might not be extended to other recovery schemes. However, in order to be effective for flooding this would need to be water-damage specific and go beyond many of the measures currently implemented. 
Additionally, the issue of enforcement would also need to be addressed with some relatively easy and cost-effective ways of checking whether properties have met (or even exceeded) the required building standards. Any change of this level is likely to need government involvement and even regulation.

\subsection{Higher and risk-reflective premiums}

In those situations where insurance is compulsory or a condition on a mortgage, the use of risk-reflective premiums (i.e. insurance premiums are highest in areas at highest risk of flooding) may be sufficient to incentivise householder actions to reduce the risk to their properties so that in turn they will receive a premium reduction. Despite this appearing to be a sensible way in which to price coverage, there were few international examples where this was working to incentivise risk-reduction behaviour. In general, where risk-reflective premiums were evident the insurance penetration was so low that it did not have a major impact upon the reduction of risk. One situation which did appear to be incentivising good practice was in Belgium. Newer properties built after September 2008 (18 months after the initiation of the insurance scheme) do not benefit from a governmental premium cap and are thus, in general, required to pay risk-related premiums. They are also excluded from receiving compensation as part of the disaster fund [12].

In other situations, such as the UK, where riskreflective premiums might have been charged the competitiveness of the market is such that premium levels are kept low and reduces incentives for individual risk reduction activity. The new Flood Re scheme implemented from April 2016 aims to change this situation and slowly increase premiums levels over the next 25 years to better reflect risk with the explicit aim of encouraging risk-reduction action [20].

\subsection{Limiting the level of indemnification or the amount compensated}

A limit on the level of indemnification offered by a scheme or the amount of compensation that any householder may receive is another way of impacting risk reduction activities, by introducing a level of 'coinsurance'. If householders are aware that they may not receive recompense for all of their losses this may incentivise them to try to reduce their risk through the uptake of household level mitigation or undertake damage-saving activities during a flood event. There are a number of different ways in which recovery approaches may limit the amount that households may receive. The most common is through the application of a deductible which is the amount that the insurant is required to pay as part of a claim (might either be a set value or a percentage of the total loss). Deductibles have long been used as instruments to control moral hazard the rational being that if policyholders have to contribute a percentage of the loss before they are fully-indemnified then they will make efforts to reduce the overall total loss [21]. Most of the international examples identified in the review had some level of deductible, although the amounts were highly variable.

High deductibles may create a larger incentive for property-owners to consider adopting mitigation measures as they will increase the amount of the total loss that they would have to bear and absorb following a flood event. Increasing deductibles, particularly in high risk areas, might be one way in which the cost-effectiveness of mitigation measures can be increased as this potential extra cost to the policyholder should be off-set against the cost of implementing mitigation. However, the extent to which policyholders will take notice of high deductibles in advance of flooding is debatable and any selfevaluated cost effectiveness will be difficult to calculate. The cost to a policyholder lies in the future and is one that may never even occur. Therefore, an increased premium (which to policyholders is a tangible cost) may be more likely to impact upon mitigation behaviour.

Another way for insurance or compensation schemes limiting their losses and/or requiring some degree of cobearing of loss is through limiting how much those affected will receive. The system in Austria is a good example of this whereby insurance is provided with an indemnification limit of 25 to $50 \%$ of the property value [12]. Italy also caps the level of the sum insured; in this case to $50 \%$ of that insured for fire [8]. In the Romanian system a limit is placed on the amount claimed on an annual aggregate basis [12]. Although this may only be applicable to the very highest risk properties this may encourage them to adopt risk reduction measures. These high-risk scenarios are also the instances where individual risk reduction measures will be most costeffective. A number of schemes (including both insurance and compensation) also have total event loss limits or fund limits in any one year (e.g. Belgium, Iceland, the Netherlands). Both of these limits will serve to increase the level of burden on the individual householder who may want or need to reduce their risk in order to reduce their losses following a flood. Arguably the former situation, whereby the limit is applied at a household level and therefore may also be known in advance of an event, maybe much more likely to incentivise action than those applied at the scheme level which is further removed from the individual. However for all limitations on the amount of recompense received, awareness is likely to remain a key issue. In order to be effective in incentivizing action (i.e. prior to being flooded) the policyholder needs to be aware of these limits and often commit to spending money to increase the resilience and resistance of their properties. 


\begin{tabular}{|c|c|c|}
\hline Instrument & Promotion of risk reduction or adaptive FRM & Examples of implementation \\
\hline $\begin{array}{l}\text { High or actuarially-priced } \\
\text { premiums }\end{array}$ & $\begin{array}{l}\text { The presence of actuarially-priced premiums } \\
\text { which in high flood risk areas may be substantial } \\
\text { may be sufficient to incentivise risk reduction } \\
\text { measures in return for a reduction in those } \\
\text { premiums }\end{array}$ & $\begin{array}{l}\text { Successful international examples are } \\
\text { limited as penetration is often low. }\end{array}$ \\
\hline \multirow{2}{*}{$\begin{array}{l}\text { Exclusions of properties from } \\
\text { insurance coverage }\end{array}$} & $\begin{array}{l}\text { Excluding newly built properties from cover is a } \\
\text { common mechanism to try to reduce increased } \\
\text { development. It may have some impact in those } \\
\text { countries whereby flood insurance is compulsory } \\
\text { (or whereby household insurance is required to } \\
\text { secure a mortgage) however in situations whereby } \\
\text { insurance is optional it may have little effect. }\end{array}$ & $\begin{array}{l}\text { e.g. Belgium, Norway, Denmark, } \\
\text { United Kingdom and France. } \\
\text { Little demonstrable impact that } \\
\text { exclusion restrains development [24] }\end{array}$ \\
\hline & $\begin{array}{l}\text { Exclusion of all properties in the highest risk } \\
\text { zones. May theory dis-incentivise the } \\
\text { construction of new properties in these areas and } \\
\text { incentivise other risk reduction activities for } \\
\text { existing properties. }\end{array}$ & $\begin{array}{l}\text { e.g. Germany - properties with a } \\
\text { probability higher than } 1 \text { in } 10 \text { years is } \\
\text { considered uninsurable - but limited } \\
\text { coverage }\end{array}$ \\
\hline $\begin{array}{l}\text { Exclusions of contents from } \\
\text { insurance coverage }\end{array}$ & $\begin{array}{l}\text { Exclusion of certain types or locations of contents } \\
\text { - conditions placed on those contents located on } \\
\text { the ground floor up to a certain height. It may } \\
\text { serve to encourage resistance activities and } \\
\text { especially for people to evacuate or raise } \\
\text { properties before or during a flood event. }\end{array}$ & $\begin{array}{l}\text { Exclusion of certain types or locations } \\
\text { of contents - conditions placed on those } \\
\text { contents located on the ground floor up } \\
\text { to a certain height. It may serve to } \\
\text { encourage resistance activities and } \\
\text { especially for people to evacuate or } \\
\text { raise properties before or during a flood } \\
\text { event. }\end{array}$ \\
\hline \multirow{2}{*}{$\begin{array}{l}\text { Restrictions on the level of } \\
\text { indemnification and the } \\
\text { percentage of the loss } \\
\text { compensated. }\end{array}$} & $\begin{array}{l}\text { Capping the level of indemnification (thus } \\
\text { limiting the amount of financial loss recovered). } \\
\text { Increased burden on householder may encourage } \\
\text { adoption of household level mitigation and/or } \\
\text { damage saving action during an event. }\end{array}$ & $\begin{array}{l}\text { e.g. Austria - insurance indemnification } \\
\text { is capped at } 25-50 \% \text { of property value }\end{array}$ \\
\hline & $\begin{array}{l}\text { Application of deductibles this is the amount that } \\
\text { the insurant is required to cover. Increasing } \\
\text { deductibles is one way to increase the cost- } \\
\text { effectiveness of implementing risk reduction. }\end{array}$ & $\begin{array}{c}\text { A very common element used within } \\
\text { both insurance and compensation } \\
\text { schemes (e.g. Belgium, France, } \\
\text { Germany) }\end{array}$ \\
\hline $\begin{array}{l}\text { Conditions placed in order to } \\
\text { receive recovery or participate in } \\
\text { an insurance scheme }\end{array}$ & $\begin{array}{c}\text { Placement and enforcement of special conditions } \\
\text { as part of an insurance scheme or to receive } \\
\text { compensation. } \\
\text { - Special building regulations (e.g. floor } \\
\text { heights, structural integrity). } \\
\text { - Direct adoption of individual property-level } \\
\text { mitigation measures. }\end{array}$ & $\begin{array}{l}\text { e.g. National Flood Insurance } \\
\text { Programme in US - directly linking risk } \\
\text { reduction and house raising to } \\
\text { insurance. } \\
\text { Currently, more commonly applied for } \\
\text { earthquakes (e.g. New Zealand, Iceland, } \\
\text { Turkey) }\end{array}$ \\
\hline $\begin{array}{l}\text { Standard retrofitting following } \\
\text { flood events }\end{array}$ & $\begin{array}{l}\text { Most direct link is through the retrofitting of } \\
\text { flood resistance and resilience following an event. } \\
\text { Although this seems a sensible option it rarely } \\
\text { occurs in practice due to the often increased cost. } \\
\text { Few ways in which this is currently offered and } \\
\text { policyholders are not compelled into taking this } \\
\text { action. }\end{array}$ & $\begin{array}{l}\text { Is offered by some insurers for instance, } \\
\text { but the shortfall in cost needs to be } \\
\text { borne by the insurant. }\end{array}$ \\
\hline
\end{tabular}

Table 1. Instruments used to promote flood risk reduction and adaptation and international examples 


\subsection{Retrofitting as standard following flood events}

Another area to explore is retrofitting resilience or resistance into properties following flood events. There is the real potential for this to impact upon the risk of properties and any future damages. However, there was very little mention of this within the international examples investigated in this study. As mentioned previously, both the schemes of both Denmark and Iceland have provisions to refuse or limit insurance cover for properties already flooded if preventative measures are not subsequently adopted [9]. However, this does not appear to be integrated into the actual recovery process, i.e. that financial recovery received from either insurance or compensation are required to restore the house in a way that reduces any future losses.

It may be easiest to make this a requirement where there are higher degrees of government intervention as it is often considered to be more expensive than restoring a property to its pre-flood condition and therefore in the short-term may cost more. This is problematic for private market insurers. Although it would be possible for them to invest more money and reduce the risk in these properties, thereby also reducing their own company's exposure, since the majority of insurance policies are renewed annually they are only guaranteed this business for a maximum of a year in the future and therefore it is not cost-effective for them to make these investments.

Affordability may be a barrier in those situations where the difference in cost needs to be covered by the individual. The Repair and Renew Grant was recently implemented by the UK government to try to overcome this obstacle and those who have been flooded can seek an additional $£ 5000$ following a flood event, which will be combined with an insurers pay out, to undertake more resilient repair of their property [22]. It is too early to really understand the success of this new approach and uptake when it was first implemented in 2013/14 was low. However, it has been reinitiated following the winter $2015 / 16$ floods where it is hoped to have a greater influence [22].

Affordability, however, is not the only obstacle. Insurers in the UK have also reported in the past other barriers to instigating more flood resilient or resistant repair following flood claims including; financial regulations which prohibit collective action and the agreement that they will adopt resilient repair as standard, some opposition from homeowners about the appearance of resilient repairs and homeowners concerns about the impact on the value of their property. This hesitancy might of course be offset in the future if property-owners knew that they could drastically reduce their future premiums or were aware that they would only be able to obtain insurance in the future if they undertook these actions

\section{Conclusions and implications}

Despite there being significant potential for some recovery measures to incentivise the uptake of flood mitigation or undertake risk reduction, evidence from existing recovery systems have highlighted that there are actually few instances where individual mitigation measures are effectively incentivised. Different recovery approaches could be doing more to integrate risk reduction into their core functions. Indeed, in particular insurers are well placed to be able to access those at risk and provide information. However, significant obstacles remain. Firstly, in many cases the promotion of risk reduction or adaptive behaviour is often a by-product of the use of the instruments in Table 1 , rather than the central purpose. Ultimately, the core focus of many of these instruments is the management and reduction of the total financial exposure of a recovery strategy (i.e. limiting total loss) rather than truly incentivising and promoting adaptive behaviour. Insurers have been slow to encourage the uptake of resilience and mitigation measures as in the past they did not see their role as a promoter of safety and equally they were concerned about a potential negative financial impact on their profits [23].

Ultimately there is also the need to consider the role, scope and priorities of insurers. The benefits of risk reduction when insurance has state involvement are clear, however for private companies, the benefits of incentivising risk reduction are more complicated. There may be some reasons for private insurers to encourage individuals to reduce their flood risk as they will reduce any damages and claims paid in the event of a claim. However, if insurers are able to effectively price risk and have adequate numbers of households buying insurance and are underwritten by reinsurance, then they may be reluctant to involve themselves in something which is external to the key role of private insurance companies which is to provide cover at a profit to their shareholders. It is important to be mindful of the agendas and priorities of private insurance companies when considering how best to incentivise individual risk-reduction.

Furthermore, we also need to consider insurers' preferences for risk reduction. Amongst private insurers there appears to be a preference for government-led or community scale risk reduction measures or the use of development control, above the adoption of individual mitigation measures or resilience. There is often the perception amongst insurers that these measures are much more effective than household-scale resilience and because they will be installed and maintained by authorities they are therefore more likely to reduce risk than other measures. They may be more likely to offer a reduction in premium when the risk-reduction action is something permanent (e.g. raising the floor level) whereby any reduction in the risk will continue to be effective over the long term. Achieving an appropriate balance between governments' providing risk management, yet also allowing the insurance market to work effectively in incentivising risk-reduction behaviour is difficult and complex; not least since ultimately 
insurers would prefer governments to invest public monies in risk reduction

There is a growing wealth of literature about the motivations and decision processes of selecting and implementing household risk reduction measures and how these could be promoted [25-29]. From the householder's perspective there remain a number of significant barriers to action. Until these are addressed merely increasing the burden on those affected by flood risk or removing the ability of a community or individual from financially recovering from flood risk appears largely insufficient to promote and incentivise adaptive behaviour. There may be a number of reasons for this failing, including:

- A general lack of awareness and/or understanding of their flood risk and the scale of any potential impacts;

- Householders lack the awareness that their insurance policy or a compensation scheme does not fully cover them from loss and therefore they are not aware that they might need to reduce their risk;

- A lack of awareness of the potential options to reduce risk and their effectiveness [30];

- Lack of knowledge on available measures for flood proofing existing buildings, and how these should be taken into account in premium calculations [25, 31];

- An inability to understand the trade-off in terms of availability/affordability of insurance and the cost of the mitigation measures $[13,30]$;

- Incentives, such as premium reductions, for implementing individual scale measures remain insufficient and are not guaranteed [32, 33].

All of these are barriers to the uptake of mitigation measures and each will need different strategies to tackle them. However, if the level or type of incentive is appropriate and sufficient then it is more likely that there will be motivation for any other barriers also to be overcome. From a private market insurance perspective the more effective mechanisms as part of the private market relate to availability and affordability of cover.

The lack of compulsion to have insurance is one key factor inhibiting the promotion of adaptation. There is much more scope for individual mitigation measures in the case of price-reflective premiums and a lack of uptake is partly due to the fact that there are very few situations where sufficiently high premiums are charged and flood insurance is a compulsory peril. Therefore, those who are unable to afford insurance are just not buying it, rather than reducing their risk (and premiums) or by making their properties more resilient to flooding. There are also a very large number of insurance schemes whereby premiums are offered at a flat-rate and therefore the scope in which to incentivise mitigation in this way, by reducing premiums, is limited.

Insurance systems where there is more government involvement may have more opportunities to add special conditions on the insurance in order to compel policyholders to take measures. However, similar to the private market where insurance is not compulsory and/or widespread it will be difficult to influence resilience to flooding on a large scale.
Despite the opportunities and the high potential for insurance to impact on mitigation, to date the outcomes appear disappointing. Insurers could be doing more to encourage the uptake of measures through clear premium or deductible incentives [25]. However, they are also well placed to offer information about those measures that might be taken to increase the resilience of a dwelling as they will have contact with policyholders at least on a yearly basis.

\section{References}

1. Sayers, P., Galloway, G., Penning-Rowsell, E., Shen, F., Wen, K., Chen, Y., and Le Quesne, T. (2012). Flood Risk Management: A strategic approach. Chapter 14 - Insurance and flood risk UNESCO and ADB on behalf of WWF and GIWP, China.

2. Priest, S.J. (2003). Responding to flood risk in the UK: A strategic Reappraisal, Unpublished $\mathrm{PhD}$ Thesis, Department of Geography, University of Southampton, pp354.

3. Hausmann, P. (1998). Floods - An Insurable Risk? Swiss Re: Zurich, Switzerland.

4. Arnell, N.W. (2000). Flood insurance in Parker, D. J. (ed.), Floods, Routledge, London, pp412-24.

5. Porrini, D. and Schwarze, R. (2014). Insurance models and European climate change policies: an assessment, European Journal of Law and Economics, 38, 7-28.

6. Mehlhorn, J. and Hausmann, P. (2012). Flood - an underestimated risk Inspect, inform, insure, Swiss Re: Zurich, Switzerland.

7. Priest S.J. (2014). Review of international flood insurance and recovery mechanisms: Implications for New Zealand and the resilience of older people, Research report for the Community Resilience and Good Ageing: Doing Better in Bad Times Project. Available online

http://resilience.goodhomes.co.nz/publications/, Accessed 09/03/15.

8. Gaschen, S., Hausmann, P., Menzinger, I. and Schaad, W. (1998) Floods - an insurable risk? A market survey, Swiss Re: Zurich, Switzerland.

9. Michel-Kerjan, E., (2001) Insurance against natural disasters: do the French have the answer? Strengths and limitations, in Working paper. 2001, Laboratoire d'économétrie, Ecole Polytechnique, Paris.

10. Fiselier, J. and Oosterberg, W. (2004). A quick scan of spatial measures and instruments for flood risk reduction in selected EU countries, Ministry of Transport, Public Works and Water Management, Directorate-General of Public Works and Water Management, RIZA Institute for Inland Water Management and Waste Water Treatment.;

11. Comité Européen des Assurances (CEA) (2005) The insurance of natural events on European markets, Property Insurance Committee, AB 5050 (06/05), CEA: Paris, France.

12. CCS (Consorcio de Compensacion de Seguros) (2008). Natural catastrophes insurance cover. A diversity of systems. CCS: Madrid, Spain. 
13. Kunreuther, H. (1996). Mitigating Disaster Losses through Insurance, Journal of Risk and Uncertainty, 12, 171187.

14. Mechler, R., and Weichselgartner, J. (2003). Disaster Loss Financing in Germany-The Case of the Elbe River Floods 2002. Interim Report IR-03-021, IIASA, Laxenburg.

15. Lamond, J. and Penning-Rowsell, E.C. (2011). A Review of International Approaches to Flood Insurance, Deliverable for Knowledge for Climate Workpackage 5, Project 5.1.

16. Federal Emergency Management Agency (FEMA) (2011). History of the National Flood Insurance Program and reform efforts, World Bank Flood Risk Conference,

http://www.gfdrr.org/sites/gfdrr.org/files/documents/ DRFI_NFIP_ReformMar11.pdf, March 17, 2011, Accessed 07/06/13.

17. Machetti, I. (2009) Risk pricing and risk transfer: a comparative overview, World Forum of catastrophe risk programmes, Taipei, 28th to 30th September 2009. Available online at http://www.wfcatprogrammes.com/c/document_libra ry/get_file?folderId=19778\&name=DLFE-1523.pdf, Accessed19/06/13.

18. King, R.O. (2013). The National Flood Insurance Program: Status and Remaining Issues for Congress, CRS Report for Congress, Congressional Research Service, Available online http://www.fas.org/sgp/crs/misc/R42850.pdf, Accessed 07/06/13.

19. Kleindorfer, P.R. and Kunreuther, H. (1999). The complementary roles of mitigation and insurance in managing catastrophic risks, Risk Analysis, 19(4), 727-738.

20. Department for Environment, Food and Rural Affairs (Defra) (2013). Securing the future availability and affordability of home insurance in areas of flood risk, June 2013, Full consultation document Defra, London.

21. Wang, J.L., Chung, C-F. and Tzeng, L.Y. (2008). An Empirical Analysis of the Effects of Increasing Deductibles on Moral Hazard, Journal of Risk and Insurance, 75(3), 551-566.

22. Repair and Renew Grant Website http://www.repairandrenewgrant.co.uk/ Accessed 09/03/15.

23. Hunter, J.R. (1994). Insuring Against Natural Disaster, NAIC Journal of Insurance, 12, 467-85.

24. Lamond, J. and Penning-Rowsell, E. (2014) The robustness of flood insurance regimes given increased risk resulting from climate change. Climate Risk Management, 2, 1-10.

25. Thieken, A.H., Petrow, T., Kreibich, H. and Merzi, B. (2006). Insurability and mitigation of flood losses in private households in Germany. Risk Analysis, 26(2), 1-13.

26. Poussin, J.K., Botzen, W.J.W. and Aerts, J.C.J.H. (2013). Stimulating flood damage mitigation through insurance: an assessment of the French CatNat system. Environmental Hazards, 12 (3-4), 258-277.
27. Poussin, J.K., Botzen,W.J.W. and Aerts, J.C.J.H. (2014). Factors of influence on flood damage mitigation behaviour by households. Environmental Science and Policy, 40, 69-77.

28. Poussin, J.K., Botzen,W.J.W. and Aerts, J.C.J.H. (2015). Effectiveness of flood damage mitigation measures: empirical evidence from French flood disasters. Global Environmental Change, 31, 74-84.

29. Hudson, P., Botzen, W.J.W., Feyen, L. and Aerts, J.C.J.H. (2016). Incentivising flood risk adaptation through risk based insurance premiums: Trade-offs between affordability and risk reduction, Ecological Economics, 125, 1-13.

30. Kunreuther, H., Michel-Kerjan, E. and Ranger, N. (2013) Insuring future climate catastrophes, Climatic Change, 118, 339-354. 30

31. Ball, T., Werritty, A. and Geddes, A. (2013). Insurance and sustainability in flood-risk management: The UK in a transitional state. Area, 45(3), 266-272.

32. Michel-Kerjan, E. and Kunreuther, H. (2011) At War with the Weather: Managing Large-Scale Risks in a New Era of Catastrophes, MIT Press: Cambridge, US. 32

33. Kleindorfer, P.R., Kunreuther, H. and Ou-Yang, C. (2012) Single-year and multi-year insurance policies in a competitive market, Journal of Risk and Uncertainty, 45, 51-78. 33

\section{Acknowledgments}

This paper presents research undertaken and supported by two research projects: a New Zealand Ministry of Business, Innovation and Employment as part of the public good science programme Community Resilience and Good Ageing: Doing Better in Bad Times (see [7]) and the European Community's Seventh Framework Programme through the grant to the budget of the STAR-FLOOD project (Grant Agreement No. 308364) www.starflood.eu. 